\title{
INVESTIGACIONES
}

\section{Jugando a la Pandemia entre los newsgames y la simulación lúdica}

\author{
Playing the Pandemic between newsgames and playful simulation \\ Jogando a pandemia entre newsgames e simulação lúdica \\ Andrea De-Santis Piras ${ }^{a}$, David Alexander Armendáriz González ${ }^{b}$ \\ ${ }^{a}$ Universitat Autónoma de Barcelona, Barcelona, España. \\ andrea.desantis@e-campus.uab.cat \\ ${ }^{b}$ Universidad Politécnica Salesiana, Cuenca, Ecuador. \\ darmendariz@ups.edu.ec
}

\begin{abstract}
RESUMEN
Los newsgames se han concebido como videojuegos creados por medios de comunicación para sensibilizar la comunidad sobre temáticas de interés, categoría que ha obviado tradicionalmente el valor informativo de otras propuestas lúdicas que conciernen temas de actualidad y que se adecúan de mejor manera al escenario digital en el cual prima la experiencia del usuario sobre la rigurosidad periodística y los estándares de producción. El propósito de este trabajo es analizar como los juegos de simulación favorecen la adquisición de información sobre temas sociales de actualidad, mediante el estudio de los aspectos mecánicos, dinámicos y estéticos de las aplicaciones de juegos para dispositivos móviles sobre pandemias durante la difusión del COVID-19, y su relación en el diseño de la experiencia del usuario. Las conclusiones evidencian como la mecánica y dinámica lúdica de este tipo de juegos proponen experiencias estéticas que estimulan el consumo de información sobre una temática de interés social, similar al impacto que pretenden generar los newsgames. El sistema dinámico de los juegos de simulación sobre pandemias se fundamenta en la capacidad del usuario de tomar decisiones en base a la información asimilada, transformando el conocimiento acumulado sobre la temática en una clave de éxito para el jugador.
\end{abstract}

Palabras claves: Simulación lúdica, juegos móviles, juegos de noticias, gamificación, experiencia del usuario, pandemia.

\begin{abstract}
The newsgames were conceived as video games created by the media to raise awareness among the community about topics of interest, a category that has traditionally ignored the informative value of other playful proposals that concern current issues and are better suited to the digital scenario in which the user's experience takes precedence over journalistic rigor and production standards. The purpose of this work is to analyse how simulation games improve the acquisition of information on current social issues, through the study of the narrative, technical and emotional aspects of the mobile games applications about pandemics during the diffusion of COVID-19, and its relationship to user experience design. The conclusions show how the mechanics and playful dynamics of this type of game propose aesthetic experiences which stimulate the consumption of information on a subject of social interest, similar to the impact that newsgames intend to generate. The dynamic system of simulation games about pandemics is based on the user's ability to make decisions based on the information assimilated, transforming the accumulated knowledge on the topic into a key to success for the player.
\end{abstract}

Key words: Gaming simulation, mobile games, newsgames, gamification, user experience, pandemic. 


\section{RESUMO}

Os newsgames têm sido concebidos como videogames criados pela mídia para sensibilizar a comunidade sobre temas de interesse, categoria que tradicionalmente ignorou o valor informativo de outras propostas lúdicas que dizem respeito à atualidade e mais adequadas ao cenário digital mundial. que prevalece sobre a experiência do usuário sobre o rigor jornalístico e os padrões de produção. O objetivo deste trabalho é analisar como os jogos de simulação favorecem a aquisição de informações sobre questões sociais atuais, estudando os aspectos mecânicos, dinâmicos e estéticos de aplicativos de jogos para dispositivos móveis em pandemias durante a disseminação do COVID- 19, e sua relação no design da experiência do usuário. As conclusões mostram como a mecânica e a dinâmica lúdica desse tipo de jogo propõem experiências estéticas que estimulam o consumo de informações sobre um tema de interesse social, semelhante ao impacto que os newsgames pretendem gerar. O sistema dinâmico de jogos de simulação de pandemias é baseado na capacidade do usuário de tomar decisões com base nas informações assimiladas, transformando o conhecimento acumulado sobre o assunto em chave para o sucesso do jogador.

Palavras-chave: Simulação lúdica, jogos para celular, jogos de notícias, gamificação, experiência do usuário, pandemia.

\section{EL ROL DE LOS VIDEOJUEGOS EN SITUACIÓN DE PANDEMIA}

Desde el comienzo del año 2020 el mundo se encuentra enfrentando el COVID-19, un virus infeccioso que ha provocado la crisis sanitaria global más grave de los últimos 100 años. En este escenario resulta de vital importancia el comportamiento de las personas, de enteras comunidades y países que revolucionan su estilo de vida, obligadas a asumir una posición ambivalente ante la pandemia: contagiado y fuente de contagio. En ambos casos la respuesta se traduce en limitaciones a la libertad personal, como de movilización, y distanciamiento social entre las personas. La comprensión de la pandemia en todas sus facetas resulta entonces como una clave de éxito en el enfrentamiento de la crisis bajo distintos puntos de vista, mientras que el desconocimiento asume la connotación de perdida, en términos de oportunidad de hacer frente a los efectos del virus, así como, literalmente, de vidas humanas.

El aislamiento social y el slogan mundialmente traducido de "Quédate en casa" proyectan un estilo de vida distinto a la cotidianidad conocida por más de 1.500 millones de personas en todo el planeta, casi la mitad de la población mundial, y el consumo de medios de comunicación reemplaza en buena medida las ocasiones de socialización. Estas herramientas posibilitan la interacción tanto en el ámbito personal como profesional, y constituyen la principal fuente de información, entretenimiento y herramienta de pasatiempo para quien está encerrado en su casa. A través de los medios se conoce y aprende mucho del entorno, incluido aquello que se considera más alejado de la realidad cultural y social (Weimann, 1999). Esta información es usada para tomar decisiones respeto a lo que sucede en el entorno, sobre todo en caso de emergencia como la pandemia actual. Sin duda, el COVID-19 se ha propagado más rápidamente en los medios de comunicación que en las personas las cuales, aparentemente, y en todos los sectores sociales, no han interpretado de manera correcta su llegada a pesar del alto número de mensajes dirigidos a la población. $\mathrm{Al}$ estado actual de la emergencia las personas y su comprensión del virus son la clave de éxito, y su comportamiento la medida más efectiva para enfrentar la pandemia.

Resulta entonces fundamental analizar cuales medios y herramientas pueden favorecer la comunicación, conocimiento y comprensión del fenómeno por parte de las personas en diferentes contextos. Los videojuegos constituyen escenarios de aprendizaje formal e informal, y asumen un significado particular en relación con la condición de aislamiento 
social que viven las personas en gran parte del mundo como medios de comunicación y extensiones de nuestro ser (McLuhan, 1996). Funcionan como pasatiempo, son usados principalmente como fuente de entretenimiento, distracción, pero, según los casos, pueden ofrecer oportunidades para la promoción de diferentes tipos de aprendizaje, permitiendo la adquisición de información y el desarrollo de competencias y habilidades especificas (DelMoral, 2014; Ibrahim, 2019).

\subsection{APRENDIZAJE ENTRE NEWSGAMES Y JUEGO DE SIMULACIÓN}

Los videojuegos son medios de comunicación con características particulares que los hacen aptos para favorecer el aprendizaje desde distintos puntos de vista (Gee, 2004, Shaffer, 2006). Son capaces de ofrecer a los jugadores experiencias de aprendizaje significativas cargadas de respuestas emocionales (Tsai, Chang, Shiau y Wang, 2019), y de informar sobre cuestiones de interés para la sociedad en cuanto favorecen la comprensión de las narrativas mediáticas construidas sobre temáticas de actualidad (Jenkins, 2003). Los videojuegos recrean situaciones realistas y las transforman en escenarios lúdicos que fomentan el aprendizaje (Del-Moral, 2014) constituyéndose como herramientas fundamentales para entender el mundo.

El interés por construir videojuegos que favorezcan el conocimiento y la reflexión de la comunidad sobre temas de actualidad nace en 2003 con la creación de September 12 th, videojuego sobre la guerra de Estados Unidos en Irak definido como newsgame por su propio diseñador (Frasca, 2013). Los newsgames son propiamente videojuegos que fusionan la actualidad relevante con la simulación lúdica (Martínez Cano, 2016). Desde las primeras aplicaciones comerciales los juegos de noticias son usados como complementos del discurso informativo de un medio de comunicación. Por lo general este tipo de juego es muy básico, poco interactivo y desactualizado. La experiencia lúdica de esta categoría de videojuegos, como afirma Sicart (2008), se fundamenta en la interacción de la ciudadanía con la información noticiosa de actualidad apuntando a la superación de la simple función lúdica del juego (p. 3), asumiendo una función política y de cambio social. Existen, pero varios desafíos a enfrentar para que este producto alcance un alto consumo, entre los cuales la obsesión de reflejar la complejidad del entorno obteniendo juegos que resultan imposibles de jugar (Frasca, 2013). El momento histórico marcado por la pandemia del COVID-19 evidencia la dificultad del género de cumplir con su cometido y de reaccionar rápidamente frente a los hechos noticiosos de relevancia, respecto a otras categorías de videojuegos que logran captar con mayor eficacia el interés del público, como los videojuegos de simulación lúdica. La lógica comercial, los intereses, y la diferencia de objetivo social que motivan el diseño de estas propuestas lúdicas no permite etiquetarlos como newsgames, pero las oportunidades que ofrecen en términos informativos sobre temáticas de interés para la sociedad evidencian la utilidad y eficacia de los juegos de simulación para la compresión de la complejidad del entorno y la realidad del mundo.

Los juegos serios o de simulación tienen como objetivo principal el aprendizaje. Esta categoría de juegos busca recrear un escenario artificial en el cual los jugadores experimentan las diferentes facetas de una situación real tomando decisiones sin consecuencias reales (Smith et al., 2020). Representan modelos dinámicos que simulan el funcionamiento de un sistema mediante la lúdica con el fin de favorecer su comprensión, evaluación y diseño. La simulación de los elementos y comportamientos del sistema busca replicar la realidad que representa utilizando varias técnicas que facilitan y vuelven más atractiva e 
interesante la exploración de los que Papert (1980) define como micromundos incubadores de conocimientos que los jugadores experimentan y construyen en base a la mecánica y dinámica del videojuego. Frente a temas relevantes y de difícil comprensión, la simulación lúdica permite una mayor información y entendimiento del hilo narrativo que se construye en otros medios de comunicación (Jenkins, 2003). Los jugadores de una simulación ponen a prueba sus habilidades mediante decisiones que se fundamentan en la información que el mismo videojuego le otorga, obligando el usuario a responsabilizarse por sus acciones con toda la seguridad del ambiente lúdico. "Los videojuegos de simulación no sólo imparten conocimientos sobre el contenido científico, sino que también practican la aplicación creativa de esos conocimientos" (Yesilyurt et al., 2019, p. 135) en una dinámica de aciertos y errores que fundamenta el proceso de aprendizaje del jugador (Urquidi y Calabor, 2014). Los conocimientos adquiridos pueden ser aplicados a la realidad en cuanto el contexto en el cual fueron asimilados mediante la simulación lúdica corresponde a la representación de un modelo de la vida real construido sobre una identidad virtual asumida por el jugador. Esta representación de sí mismo dentro de una realidad reconstruida y simplificada define una identidad proyectiva al contexto capaz de evolucionar y desarrollar nuevas identidades con nuevas rutinas y conocimientos adquiridos. En la práctica, la simulación permite la asimilación de pautas de comportamientos concretos respecto al relato especifico construido en base a la nueva identidad (Alonso y Navazo, 2019) creada en el contexto de un modelo de vida real. Mediante el potenciamiento de la capacidad cognitiva provocado por la proyección de nuestra mente a un escenario abstracto, la identidad virtual resulta alcanzable, cargada de las expectativas del jugador respecto al objetivo del juego, y capaz de generar un efecto, provocar emociones y sensaciones producto de la acción del jugador.

La simulación lúdica no es prerrogativa de los juegos serios. En internet, de hecho, la mayoría de videojuegos que se define de simulación responden a fines de tipo comercial y entretenimiento más que de aprendizaje. El campo de la investigación en el aprendizaje basado en el juego implica el estudio tanto de juegos serios con fines educativos como de las expresiones lúdicas dirigidas principalmente al entretenimiento de las personas en contexto formales como informales (Persico et al., 2019). En estos términos, y en función de la crisis causada por la difusión del COVID-19, resulta interesante la valoración de la simulación lúdica y los videojuegos en línea como instrumentos útiles para generar aprendizaje sobre la pandemia y fomentar un comportamiento adecuado respecto a las acciones puestas en marcha para hacer frente a la emergencia.

\subsection{JUGAR A LA PANDEMIA: HISTORIA DE LOS VIDEOJUEGOS SOBRE DIFUSIÓN GLOBAL DE UN VIRUS INFECCIOSO}

La historia de los videojuegos en línea sobre pandemias provocadas por enfermedad infecciosa real o realista es relativamente corta. El primer producto lúdico en línea que se registra es Pandemic 2, un videojuego gratuito inspirado y basado en las reglas de Pandemic, un juego de mesa cooperativo lanzado al mercado por Z-Man Games en el año 2007 en el cual los jugadores deben encontrar la cura a cuatro enfermedades antes de que se desencadene la pandemia. En Pandemic 2, a diferencia del juego de mesa, el jugador debe elaborar una estrategia para favorecer la propagación de un virus agresivo por todo el planeta en base a una serie de noticias informativas, con el fin de aniquilar la humanidad antes de que se encuentre una cura. Desde la aparición del coronavirus COVID-19, la 
página web que aloja este videojuego ha registrado un incremento de visitas del $3.500 \%$ en comparación con los dos meses anteriores, alcanzando más de 140.000 partidos en línea hasta la mitad de marzo de 2020 (Leskin, 2020).

En 2009 aparece Killer Flu, un newsgame encargado por la Red de Virología Clínica del Reino Unido y producido por Persuasive Games en asociación con Traffic Games de Escocia. El videojuego nace con relación a la aparición y difusión en el mismo año de la gripe H1N1 (porcina) y la necesidad de informar a la población respecto a la diferencia entre un virus de gripe estacional y uno capaz de generar una pandemia. Mediante Killer Flu la Red de Virología Clínica del Reino Unido propone explicar el funcionamiento de una infección viral y su escasa capacidad de infectar a todos en un área determinada a pesar de sus mutaciones. Similar a la dinámica de juego de Pandemic, el jugador es un virus que infecta a las personas con el objetivo de contagiar al menos el $25 \%$ de la población mundial. Las opciones de interacción que esta propuesta ofrece al usuario son limitadas respecto a otros juegos, y su fin es netamente educativo. Killer Flu es el único newsgame que se identifica en esta reconstrucción histórica y en la actualidad no está disponible para los jugadores de la red ${ }^{1}$.

La experiencia de mayor éxito concerniente a la temática es Plague Inc., videojuego que presenta una combinación de estrategia y simulación de la realidad desarrollado por Ndemic Creations y lanzado al mercado en el 2012. Respecto a Pandemic 2 y Killer Flu, este videojuego se encuentra disponible para varias plataformas y dispositivos como IOs, AndrodiD, PC, Mac, XboxOne, PS4 y Linux, lo que explica su rápida explosión en términos de descargas en los varios app stores y partidas jugadas, debida principalmente a la difusión del COVID-19 y la existencia de una pandemia real. Como Pandemic 2, que inspiró su diseño, Plague Inc. plantea una situación realista en la cual el jugador debe crear un patógeno e infectar el mundo con el objetivo de exterminar la población antes del descubrimiento de una cura. Según los datos de la misma empresa, Plague Inc. en 2019 fue jugado por 135 millones de personas en todo el mundo y su popularidad en 2020 ha incrementado notablemente tanto de llegar a ser prohibido por el gobierno de China en febrero del mismo año (Ndemic Creations, 2020). A pesar de proponer al jugador la aniquilación de la humanidad como objetivo, este videojuego ha sido reconocido por su valor informativo y por contribuir, según los Centros de Control y Prevención de Enfermedades de EE.UU., a sensibilizar los jugadores sobre epidemiología, transmisión de enfermedades y pandemias creando "un mundo convincente que involucra al público en temas serios de salud pública" (Luna, 2020).

Sucesivamente a la aparición de Plague Inc. y al éxito relacionado con los brotes de los virus del Mers en el 2012, y Ebola en el 2014, se registra la aparición de videojuegos que tratan a las pandemias causadas por virus infecciosos reales y realistas. En particular, a partir de 2018 se intensifica el lanzamiento de aplicaciones para dispositivos móviles de esta categoría temática de videojuegos, tendencia en significativo aumento desde el comienzo de 2020 con la difusión mundial del COVID-19, como demuestra la aparición de Coronavirus Attack presentado el 23 de abril de 2020 por MythZsGame. En controtendencia, la empresa Epic Games decidió no ofrecer gratuitamente en su tienda virtual a Pandemic, acontecimiento previsto y anunciado para el mes de febrero 2020. El videojuego, presentado en 2016 y comercializado bajo la modalidad de pago, concentra el jugador en el tratamiento de infecciones y la búsqueda de curas en un escenario pandémico, de igual manera que el homónimo juego de mesa con el cual comenzó este breve recorrido histórico.

http://persuasivegames.com/game/killerflu 
El objetivo del presente trabajo es estudiar cómo funcionan las diferentes componentes del juego y se interrelacionan con el fin de crear la experiencia de juego para el usuario en merito a la pandemia. Al centro del estudio se encuentran la narrativa y las características sistémicas y de proceso que permiten la experimentación de situaciones y emociones cercanas a la realidad en los mobile games de simulación sobre pandemias causadas por virus infecciosos reales y realistas. A parte del interés en los juegos serios demostrado por el Centro de Investigación de Enfermedades Infecciosas de la Universidad de Cambridge, la literatura sobre el uso de videojuegos para informar y educar sobre la pandemia es escasa y no considera cuestiones como el diseño y la experiencia del usuario desde el punto de vista de las emociones y sensaciones que motivan su participación en el juego y estimulan la asimilación de información y el aprendizaje (Kurahashi, 2019; Smith et al., 2020). Este discurso resulta relevante si se considera que los estudios en merito enfocan su atención en los videojuegos que por definición son serios o educativos, excluyendo aquellos etiquetados simplemente como entretenimiento.

\section{DISEÑO Y MÉTODO}

Los dispositivos móviles constituyen en la actualidad una importante herramienta de entretenimiento en la cual las personas invierten recursos y tiempo. Mediante la descarga de aplicaciones lúdicas cada usuario puede disponer de varias opciones de juego en su dispositivo móvil interconectándose con el ecosistema mediático multiplataforma del cual los videojuegos son parte integrante y funcional. En 2019, la estima de los ingresos producidos por los juegos móviles abordaba los $\$ 68.5$ mil millones, el $45 \%$ del mercado global de juegos. El 80\% de este monto corresponde a los juegos de teléfonos inteligentes, y los juegos para tableta representan el 20\% restante (NEWZOO, 2019, p. 11).

El presente análisis de los mobiles games sobre pandemias se concentra en aquellas aplicaciones para dispositivos móviles accesibles de manera gratuita por cualquier usuario. En particular, el estudio toma en cuenta las aplicaciones de juegos móviles más descargadas y mejor evaluadas en la tienda virtual de Google Play en el mes de marzo de 2020, en pleno desarrollo de la pandemia del COVID-19. Los resultados de búsqueda que ofrece Google Play se basan en la popularidad y uso de la aplicación, además de las valoraciones de los usuarios y los anuncios de aplicaciones relacionadas con los criterios de búsqueda. La búsqueda de juegos en la tienda virtual se ha realizado utilizando los términos "pandemia" y "pandemic". Para el estudio se seleccionaron únicamente las aplicaciones que cumplían con tres características específicas: i) la temática del juego es sobre pandemia; ii) la pandemia es causada por virus reales o realistas; iii) la gratuidad de la descarga y acceso al juego. La selección conduce a una muestra de cinco aplicaciones de la cuales tres son totalmente gratuitas y dos son comercializadas mediante un modelo de negocios freemium con servicios gratuitos y pagados al mismo tiempo (Tabla 2). "Éstos pueden ser adquiridos por el jugador con el fin de avanzar en el juego o comprar accesorios y recursos para desenvolverse dentro de sus distintos niveles de acceso y de juego" (De Santis-Piras y Morales Morante, 2019, p. 72). El universo considerado incluye únicamente los juegos que tratan de pandemias inspiradas en hechos reales o que simulan su desarrollo con un trasfondo de realidad. En la práctica, se trata de las pandemias causadas por virus infecciosos que presentan características reales o potencialmente reales, por lo que se 
excluyen aquellas aplicaciones lúdicas que construyen narraciones sobre acontecimientos irreales o surreales como en el caso de monstruos, alienígenas y zombies.

Con el fin de analizar la construcción discursiva de los mobile games parte de la muestra y su relación con la experiencia del usuario se adopta el modelo metodológico MDA (mechanics, dynamics, aesthetics) propuesto por Hunicke, Leblanc y Zubek (2004) como una herramienta para comprender los juegos entre su diseño y desarrollo, la crítica y la investigación técnica, facilitando su descomposición y estudio. El modelo MDA considera tanto la perspectiva del jugador como la del/la diseñador/a abarcando aspectos distintos como los mecanismos y reglas básicas del juego, los objetivos y las experiencias deseadas para el usuario. Al concebirlos como artefactos es posible analizar los videojuegos de la muestra como sistemas capaces de construir comportamientos que conducen a experiencias significativas para el jugador.

Los tres componentes principales del modelo y su interacción configuran el resultado deseado por el/la diseñador/a y preparado para ser experimentado por el usuario. El primer componente, la mecánica, se refiere al sistema de juego y su lógica basada en las reglas constitutivas que permiten el funcionamiento de la aplicación, y las reglas operativas otorgadas al usuario para que pueda jugar (Herrero-Curiel y Planells de la Maza, 2020). Mediante el uso de los varios recursos el usuario pone en función el sistema con sus estrategias y acciones, dando vida al juego. Esta es la dinámica del juego, el segundo componente del modelo. Finalmente, la "estética describe las respuestas emocionales deseadas evocadas en el jugador cuando interactúa con el sistema del juego" (Hunicke, Leblanc y Zubek, 2004, p. 2). La experimentación de estados emocionales (estética) conduce el usuario a un aprendizaje sobre el sistema de juego y a la formulación de estrategias y acciones específicas que le permitan cumplir con su objetivo (dinámica), basadas en la experiencia y conocimiento acumulados sobre el funcionamiento del mismo sistema (mecánica).

Para la aplicación del modelo se determinaron las categorías de análisis en función de sus tres componentes: mecánicas, dinámicas y estéticas. Para ello se ha creado una herramienta de recolección específica (Tabla 2) para identificar los elementos referentes a cada categoría en base al modelo de investigación MDA.

Tabla 1. Categorías de análisis del modelo MDA

\begin{tabular}{|l|l|l|}
\hline \multicolumn{1}{|c|}{ MECÁNICAS } & \multicolumn{1}{c|}{ DINÁMICAS } & \multicolumn{1}{c|}{ ESTÁTICAS } \\
\hline Objetivo & Lógica de juego & Tipo de estética: \\
\hline Reglas de juego & Desarrollo del juego & Sensación \\
\hline Limitaciones del juego & Tipo de juego & Fantasía \\
\hline Niveles de juego & Nivel de Información & Narrativa \\
\hline Dificultad & & Reto/dificultad \\
\hline Acciones posibles para el jugador & & Compañerismo \\
\hline Activos/Recursos & & Descubrimiento \\
\hline Tutoriales & & Expresión \\
\hline Tiempo & & Inmersión \\
\hline
\end{tabular}

Fuente: Elaboración propia, con base en Hunicke, Leblanc y Zubek (2004). 
La aplicación del modelo al análisis de mobile games permite estudiar cada elemento por separado ofreciendo "una visión de cómo estos funcionan y se interrelacionan para crear la experiencia de juego del usuario" (Martínez-Cano, Cifuentes-Albeza y Ivars Nicolás, 2019, p. 1479). Mediante el análisis de las características de los juegos seleccionados y de su propuesta informativa para el jugador, se evalúa el potencial de los juegos de simulación como herramientas para incrementar el conocimiento y concientizar el público sobre este tipo de pandemias.

\section{RESULTADOS}

Las aplicaciones para dispositivos móviles sobre pandemia parte de la muestra corresponden a videojuegos clasificados por la misma tienda virtual como de simulación. El análisis de los juegos seleccionados se realizó entre el 24 de marzo y el 30 de abril de 2020. Los indicadores ofrecidos por la tienda virtual representan el uso, la popularidad y la opinión de los jugadores en función de su experiencia directa y su valoración sobre el videojuego ${ }^{2}$.

Tabla 2. Aplicaciones de mobile games sobre pandemia parte de la muestra

\begin{tabular}{|l|c|l|c|c|c|}
\hline \multicolumn{1}{|c|}{ Juego } & $\begin{array}{c}\text { Año de } \\
\text { creación }\end{array}$ & $\begin{array}{c}\text { Modelo de } \\
\text { negocio }\end{array}$ & Descargas & Evaluación & $\begin{array}{c}\text { Número de } \\
\text { evaluaciones }\end{array}$ \\
\hline Plague Inc. & 2012 & Freemium & $50.000 .000+$ & 4.3 & $3,189,956$ \\
\hline Outbreak - Infect The World & 2018 & Gratuito & $100.000+$ & 4.3 & 1,698 \\
\hline Virus Antidote - Plague Infection & 2020 & Gratuito & $500+$ & 1.7 & 25 \\
\hline MediBot Inc. Virus Plague & 2018 & Gratuito & $50,000+$ & 3.3 & 314 \\
\hline Idle Plague & 2020 & Freemium & $100,000+$ & --- & --- \\
\hline
\end{tabular}

Fuente: Tienda virtual de Google Play. Recuperado el 24 de marzo de 2020.

Las aplicaciones fueron analizadas en el mes de abril de 2019 por los dos autores del trabajo en doble ocasión y por separado. Al realizar la primera revisión se procedió con un análisis de las fichas completadas por cada autor y por cada una de las aplicaciones considerando los elementos y categorías del modelo MDA (Tabla 1). Al detectar las posibles diferencias o ausencias del registro los autores volvieron a analizar cada aplicación y validar la información recopilada en las fichas. Los resultados obtenidos permiten la evaluación de cada uno de los elementos que componen un mobile game y el análisis de su relación en la creación de la experiencia del usuario.

https://play.google.com/about/comment-posting-policy/ 
Se trata de un videojuego de estrategia desarrollado y lanzado por Ndemic Creations en el año 2012 a raíz de la difusión mundial de los virus H1N1 (2009) y Ébola (2014). El videojuego alcanza su mayor éxito con otra infección de la familia coronavirus, el COVID-19, resultando como la aplicación lúdica más descargada en la plataforma Google Play en China, causa de su sucesiva censura en el país ${ }^{3}$. El juego consiste en una simulación en la cual el usuario crea y desarrolla un patógeno con el fin de extinguir a la humanidad iniciando por la infección del paciente cero. Para lograr su objetivo debe evolucionar la plaga y mejorar su capacidad de adaptación a diferentes ambientes dentro del tiempo límite en el cual los humanos encontrarán una cura. El juego es organizado por etapas, permite seleccionar entre siete tipos de epidemias y prevé cuatro grados de dificultad que se desbloquean una vez el jugador haya experimentado todas las modalidades de juego.

Figura 1. Imagen de portada de Plague Inc.

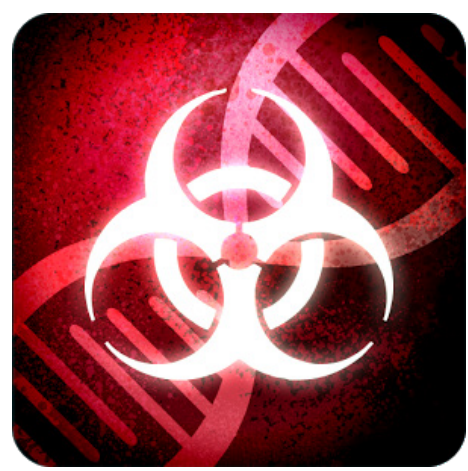

Fuente: Tienda Virtual de Google Play.

Este vínculo evidencia el rol central de la información en el juego en cuanto el usuario debe consumirla y utilizarla para poder avanzar de nivel. El conocimiento generado en el usuario produce una concientización sobre la pandemia y sus efectos. En cada nivel el comportamiento de enfermos, médicos y de la población es diferente simulando las varias etapas de desarrollo y difusión de un virus real como el COVID-19. El jugador conoce cuales son los posibles efectos del virus en función de las decisiones y comportamientos de la población mundial, de una forma muy similar a lo que están experimentando en este momento los ciudadanos del mundo. La dificultad en el juego se divide en: causal, normal, brutal y mega-brutal. El proceso de aprendizaje de la mecánica de juego es bastante sencillo: un tutorial interactivo y experiencial acompaña el jugador durante la primera partida otorgando la información necesaria y guiando sus primeros pasos para que las acciones posteriores sean lo más intuitivas posibles. Desde el punto de vista de la dinámica, la lógica del juego conduce al usuario por las varias etapas. Una vez seleccionado el país en

https://www.ndemiccreations.com/en/news/173-statement-on-the-removal-of-plague-inc-from-the-china-app-store 
el cual iniciar el contagio, y a medida que este va creciendo, se puede mejorar la capacidad del virus para transmitir la enfermedad mediante la recolección de puntos generados por la efectividad del patógeno al infectar y matar la mayor cantidad de personas en el mayor número de territorios. Los aspectos por modificar se dividen en: transmisión del virus, síntomas y habilidades.

La dinámica del juego es marcada por el límite de tiempo de cada partida representado por años virtuales que trascurren a cierta velocidad ejerciendo una presión sobre el jugador que debe tomar decisiones y actuar con la mayor rapidez posible. El entero proceso de juego prevé que cada acción o decisión se fundamente en información que debe ser minuciosamente analizada y contrastada con la base de noticias integradas en el juego. La dinámica se centra en la efectiva transmisión y apropiación de conocimiento por parte del usuario que lo usa para tomar decisiones y seleccionar nuevas vías de transmisión, desarrollar habilidades o producir nuevos síntomas. La dificultad aumenta, así como la capacidad de asimilar y procesar datos necesarios, capturando por completo la atención del jugador e involucrándolo en importantes problemas de salud pública, prevención y control de enfermedades con escenarios posibles en el mundo real.

La mecánica y dinámica de juego permiten una simulación de posibles escenarios que en la actualidad resultan mucho más realistas de las anteriores versiones del coronavirus las cuales no han alcanzado el grado de pandemia a pesar de su difusión planetaria. El videojuego se fundamenta en una narrativa de inmersión total del usuario en el escenario de simulación enfocando sus esfuerzos en el reto de alcanzar la meta antes del tiempo límite. La interacción del jugador con el sistema de juego estimula respuestas emocionales en las cuales el deseo de victoria se traduce en la muerte de los habitantes del planeta. No existe una competencia directa con otros jugadores en cuanto los antagonistas son parte de la misma dinámica del juego, la única medida de comparación es el puntaje obtenido y su inclusión en un ranking general. Sin duda, la presión que ejerce la combinación de velocidad a incremento gradual y el límite de tiempo obliga el jugador en enfocar sus esfuerzos en objetivos de aprendizaje puntuales que le consienten avanzar en el juego. El desafío consiste en saber utilizar la información correcta de manera adecuada antes que el mundo encuentre una manera de combatir el virus, estimulando el conocimiento de la pandemia, sus características, evolución, efectos y consecuencias.

\subsection{OUTBREAK - INFECT THE WORLD: ¿SALVAR O EXTERMINAR A LA HUMANIDAD?}

La propuesta lúdica es muy similar a Plague Inc. aunque presenta una gran diferencia en términos de objetivos de juego puesto que en Outbreak - Infect The World existen dos modos diferentes de juego: en contra o a favor de la humanidad. En el primer caso la dinámica de juego es la misma de Plague Inc., exterminar la humanidad mediante la difusión mundial de un virus. En el segundo escenario un patógeno es el enemigo y el jugador debe recopilar toda la información necesaria para tomar acciones que le permitan salvar la humanidad de la extinción mediante el descubrimiento de una cura. En esta modalidad es posible tomar medidas como el cierre de fronteras, aeropuertos y puertos marítimos. 
Figura 2. Imagen de portada de Outbreak - Infect the World

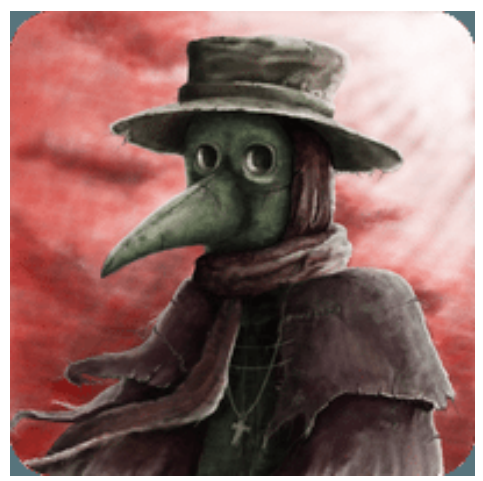

Fuente: Tienda Virtual de Google Play.

El jugador tiene a disposición herramientas que le permiten realizar acciones como la actualización de los métodos de prevención de enfermedades o, incluso, el uso de las misiones de las Naciones Unidas para ayudar países afectados e implementar campañas de educación y concientización de las personas mientras se busca y desarrolla la cura. Cada partida tiene un tiempo límite terminado el cual se pierde automáticamente. La mecánica del juego considera una importante cantidad de información que es ofrecida al usuario en tiempo real incluyendo datos como: población mundial total, regiones saludables e infectadas, regiones extintas e irrecuperables, así como la cantidad diaria de personas curadas, infectadas y fallecidas. El jugador da sus primeros pasos en la aplicación gracias a un tutorial informativo de tipo textual, menos interactivo que la versión experiencial pero muy útil para generar aprendizaje sobre el juego y la pandemia. A diferencia de Plague Inc., Outbreak - Infect the World incluye una opción que puede cambiar radicalmente el escenario de la pandemia mediante catástrofes naturales que causan una propagación más rápida y eficiente de la enfermedad. El juego tiene tres niveles de dificultad seleccionables según la voluntad del jugador en cuanto no prevé muro de costo o modelo pay to win, ofreciendo la oportunidad de personalizar la partida desde el inicio.

La evolución de la cura, el virus o bacteria requiere un planteamiento estratégico del jugador que toma decisiones en base a la información noticiosa y recursos otorgados por el juego, además de sus conocimientos previos de geografía, ciencias e historia. La dinámica del juego obliga al usuario a informarse constante y rápidamente para enfrentar la complejidad que incrementa en función de las características del virus. Estas resultan mucho más detalladas que en Plague Inc. y son dividas en tres grupos: transmisión (directa o indirecta); resistencia (a medicamentos, clima e investigación) y síntomas (generales, sistema nervioso, sistema digestivo, sistema respiratorio, sistema circulatorio y piel). De otra parte, al seleccionar la modalidad que prevé la salvación de la humanidad el jugador selecciona y combina elementos relacionados con vacunas, prevención de enfermedades y estándares sanitarios.

La estética del juego diseña respuestas emotivas muy similares a Plague Inc. por el límite de tiempo y la interfaz gráfica que muestra el avance de una partida en porcentaje 
apuntando hacia su finalización. Outbreak - Infect the World comparte con esta aplicación también la calificación de los jugadores de Google Play obteniendo el puntaje más alto de la muestra $(4,3)$, aunque es necesario evidenciar que entre ambas existe una diferencia de aproximadamente cincuenta millones de descargas (Tabla 2). El escenario es de fantasía, pero sumamente realista gracias a la inmersión total del jugador en la narración construida sobre las noticias y que reconstruye una situación de pandemia. Sin la oportuna adquisición y comprensión de la información y, pues, del problema, el jugador no puede alcanzar la proyección emocional esperada en la concepción del juego que propone una doble perspectiva de aprendizaje: aprender a matar o aprender a salvar.

\subsection{VIRUS ANTIDOTE - PLAGUE INFECTION: LA CURA PARA LA PANDEMIA}

Virus Antidote - Plague Infection es un juego de estrategia que tiene como único objetivo la salvación de la humanidad. El videojuego presenta una interfaz sencilla que no ofrece información sobre la mecánica del juego, y no existe tutorial que explique las reglas y favorezca su contextualización en la narrativa. Existe un solo nivel de dificultad y el tiempo no representa un factor relevante para la consecución del objetivo en cuanto avanza solamente cuando el usuario está jugando. Siguiendo la misma lógica de los casos anteriores, en Virus Antidote - Plague Infection el jugador toma decisiones en base a la información de carácter noticioso buscando adquirir elementos que le ayuden a encontrar la cura para la pandemia. A diferencia de los más famosos ejemplos, no presenta una narración articulada que proyecte el jugador en la simulación de una pandemia real, limitándose a comunicados automáticos y repetidos con la misma secuencia en cada partido.

Figura 3. Imagen de portada de Virus Antidote - Plague Infection

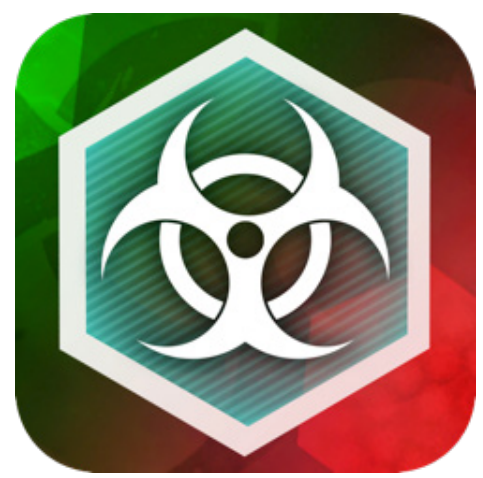

Fuente: Tienda Virtual de Google Play.

La interacción del usuario con el juego es limitada a la obtención del dinero virtual necesario para comprar y probar elementos que mejoren su vacuna. Esta acción puede ser realizada sin la necesidad de seguir la dinámica informativa en cuanto el dinero se obtiene con un click en un botón. Las opciones de mejora que el jugador puede adquirir mediante el dinero acumulado son de tres categorías: extensiones que limitan el efecto del virus; 
síntomas que se pueden reducir y aliviar; habilidades del virus reducidas por la vacuna. A pesar de presentar información sobre características propias de virus reales, el jugador no debe necesariamente seguir una lógica de juego en la toma de decisiones. Las opciones de mejora de la vacuna pueden ser adquiridas sin un orden preciso en cuanto la fórmula perfecta se consigue obteniendo todos los elementos a disposición.

La ausencia de una estrategia y de la necesidad de utilizar la información a disposición para la toma de decisiones obstaculizan la inmersión del jugador en la simulación de la pandemia y la comprensión de los aspectos relacionados. Su atención es enfocada sobre un objetivo positivo, salvar la humanidad, pero su aporte es superficial. El virus es único, la cura también y el jugador solo debe seguir un proceso en el cual la mecánica se superpone a la dinámica de juego y se requiere un esfuerzo mínimo del usuario, restando realismo a la narración. Virus Antidote - Plague Infection es el mobile game de la muestra que, al momento de la recolección, obtiene la menor calificación por parte de los usuarios de Google Play (Tabla 2), y el único que registra críticas por su excesiva similitud con otros juegos y por atraer potenciales jugadores presentándose como propuesta lúdica con fines educativos. Esta aplicación ya no se encuentra disponible en Google Play aproximadamente desde la tercera semana del mes de abril de 2020.

\subsection{MEDIBOT INC. VIRUS PLAGUE - PANDEMIC GAME: SIMULACIÓN DEL OFICIO MEDICO}

MediBot Inc. Virus Plague - Pandemic Game es un juego realista y estratégico en el cual el jugador simula ser un/a médico que enfrenta una plaga infecciosa masiva desconocida dentro de un hospital con el objetivo de descubrir una cura y salvar la humanidad. La partida es individual y el jugador guiado por un tutorial informativo que explica la dinámica del juego. En base a un análisis exhaustivo de los casos clínicos que se le presentan, el médico tiene el deber de detectar el tipo de enfermedad que afecta sus pacientes y el tratamiento adecuado. Para determinar la cura el usuario necesita asimilar y procesar la información de cada paciente y las pistas relacionadas mediante la visualización de tarjetas descriptivas con sus datos médicos.

Figura 4. Imagen de portada de MediBot Inc. Virus Plague

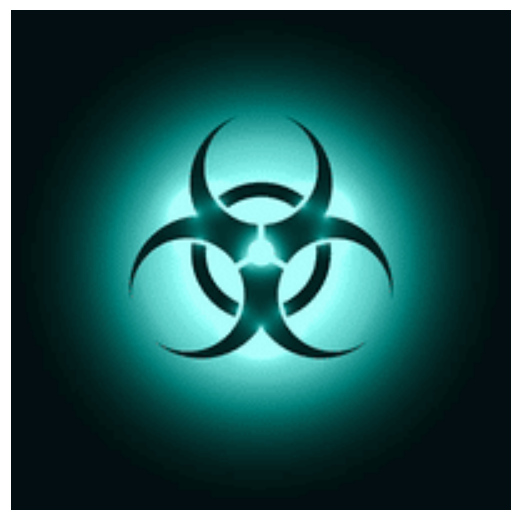

Fuente: Tienda Virtual de Google Play. 
El juego ofrece información respecto al clima, el tipo de patógeno y las modalidades de propagación del mismo. Sin la comprensión y el correcto relacionamiento de estos datos es imposible derrotar el virus y cumplir con el objetivo de salvar la humanidad. El número de intentos para identificar enfermedad y cura es limitado, y se reduce con el nivel de dificultad. Dispone de ayudas o comodines que permiten descartar hipótesis y direccionar su investigación hacia la solución, pero también estas se reducen en relación con la dificultad de juego.

La dinámica de este juego es vinculada al consumo de una gran cantidad información por parte del jugador que dispone de tiempo ilimitado para realizar sus análisis, estudiar los datos que recolecta el número de veces que considere necesario, analizar cada paciente y elaborar la cura. El juego resulta de mayor accesibilidad para aquellos usuarios que cuentan con conocimientos previos en materia de medicina y enfermedades infecciosas. La acción del jugador se limita a responder las preguntas planteadas por la aplicación, sin embargo, la interacción constante con información médica específica en un contexto simulado estimula un conocimiento real sobre argumentos complejos y la habilidad de relacionarlos para comprender su naturaleza, características, efectos y consecuencias. Existe una interacción entre usuarios mediante la competencia directa en el ranking interno del juego construido con el puntaje obtenido en base a los casos resueltos. Los puntos pueden ser canjeados por ayudas o comodines asumiendo la doble función de incentivo y recurso para el juego.

La experiencia diseñada para El usuario de MediBot Inc. Virus Plague - Pandemic Game se enfoca en un objetivo educativo y a un público de jugadores/as interesados en ampliar sus conocimientos en el ámbito médico, en particular sobre virus infecciosos. La simulación lúdica de esta aplicación proyecta el jugador en un contexto realista que le permite experimentar curiosidad e intriga asociadas al placer de la victoria por salvar vidas y la obtención de recompensas. La narración enfoca la atención del juego y lo/la compromete a llevar a cabo su misión sacrificando tiempo y esfuerzos, influyendo sobre la valoración $(3,3)$ expresada en la tienda virtual de Google Play (Tabla 2). En términos estéticos, este mobile game sugiere un aprendizaje significativo para el usuario procedente del desafío informativo que debe enfrentar y la experiencia que adquiere construyendo su identidad virtual con la asunción del rol del médico.

\subsection{IDLE PLAGUE: PERSONIFICAR EL VIRUS}

La plaga ociosa es un juego de simulación que propone al jugador asumir el rol de un virus que infecta y mata seres humanos con el objetivo de exterminar un grupo de personas virtuales. A diferencia de videojuegos como Plague Inc. y Outbreak - Infect the World, el jugador no gestiona la difusión de una pandemia en varios territorios o países porque su perspectiva de virus es experimentada desde el cuerpo del portador de la enfermedad en el cual se encuentra.

El juego inicia con la infección del paciente cero y una interfaz que muestra la perspectiva de uno o varios microorganismos en el torrente sanguíneo del huésped. Al ingresar dentro del organismo de cada paciente el jugador tiene diferentes opciones para incrementar la letalidad del patógeno (microbios, órganos, potenciadores y mutaciones) las cuales son desbloqueadas mediante el canje de los puntos acumulados en el desarrollo de la infección en las varias áreas del cuerpo del huésped. Cuando el virus logra afectar todo el organismo puede terminar con la vida del infectado utilizando una poción o escancia 
de huésped la cual actúa como veneno definitivo. Concluido su trabajo el virus salta a otro huésped y continúa propagándose por la red hasta conseguir la muerte de todos los contactos señalados en el mapa de la interfaz, lo que significa el inicio de una nueva misión. Para evolucionar y adquirir más habilidades el virus recolecta tres tipos de recursos, cada uno con un rol específico: monedas (de fácil recolección y necesarias para la adquisición de habilidades), diamantes (permiten desbloquear habilidades y avanzar en el juego), poción o esencia de huésped (arma para matar a un individuo).

Figura 5. Imagen de portada de Idle Plague

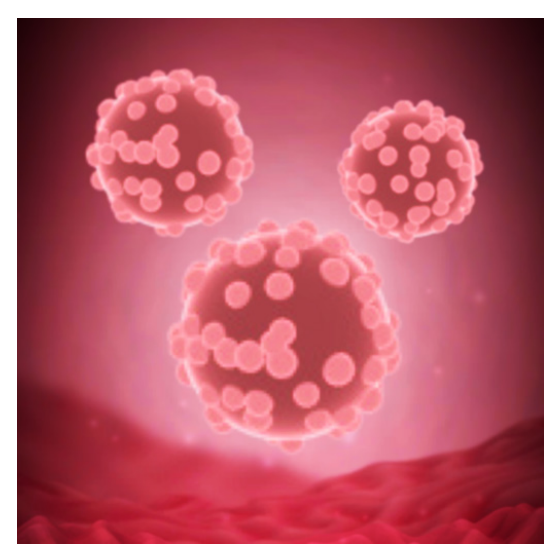

Fuente: Tienda Virtual de Google Play.

La dinámica de juego de Idle Pague es interactiva y experiencial iniciando desde el proceso de formación del jugador que prevé la lectura de textos explicativos, videos e indicaciones interactivas que acompañan el desarrollo de su experiencia lúdica. Sin duda, su participación en el proceso no prevé una narración realista de la pandemia y una profundización de los aspectos relacionados al contagio de un virus real. El jugador puede mejorarse como virus y ampliar su efecto, pero la modalidad de juego prevé que lleve a cabo la infección tocando rápida y repetidamente la pantalla del dispositivo móvil con el fin de liberar las toxinas y afectar el mayor número de órganos posible. De esta manera, obtiene puntos que usa para evolucionar y cumplir con su misión y, consecuentemente, acceder a un nuevo desafío en el cual utilizar las habilidades y recursos adquiridos infectando una nueva red de personas. El tiempo es ilimitado y el proceso de juego es de larga duración, marcado por el cumplimiento de logros y tareas diarias que permiten obtener recursos y alcanzar el mortífero objetivo. Al tratarse de una aplicación que funciona según la lógica freemium, el jugador tiene la posibilidad de pagar para avanzar más rápido en el juego obteniendo mejoras instantáneas que reducen el tiempo de la misión.

En Idle Plague la información sobre el virus y su difusión tiene un rol secundario respecto a las otras aplicaciones analizadas. El nivel de asimilación y procesamiento de datos por parte del usuario es reducido en cuanto el proceso de toma de decisiones es intuitivo y la narración del contagio desconectada de las acciones que permiten avanzar 
hacia la meta. Desde el punto de vista de la experiencia estética que diseña para el usuario, el juego evoca respuestas emotivas relacionadas con el placer de cumplir logros cotidianos, obtener recompensas y acumular los recursos cada vez más necesarios para avanzar en el juego. El objetivo comercial de la aplicación apunta a la monetización mediante el desarrollo de la dinámica de juego, por lo que a pesar de acumular muchos recursos estos parecen insuficientes llevando el usuario a experimentar la presión y estrés de seguir recolectándolos. Sin embargo, no hay manera de perder la partida, por lo que la carga de tensión para el jugador es inferior respecto a la que se percibe mediante la condición limitada de tiempo.

El escenario simulado por Idle Plague proyecta la infección de un cuerpo humano real pero no una respuesta realista del jugador que es guiado hacia una experiencia similar a la propuesta lúdica de los casual games (De Santis-Piras y Morales Morante, 2019). Este videojuego no exige un profundo entendimiento de su mecánica y dinámica para ser jugado, y la ausencia de una narración solida acerca del virus y la infección no permite una inmersión en la simulación y un aprendizaje significativo acerca de los aspectos relacionados con la pandemia. Es la única aplicación de la muestra que no presenta un registro de valoraciones de calidad por parte del usuario hasta la fecha de presentación de este trabajo.

\section{DISCUSIÓN Y CONCLUSIONES}

El presente trabajo, mediante el análisis de la mecánica, dinámica y estética de cinco aplicaciones de videojuegos para dispositivos móviles sobre difusión global de un virus infeccioso, ofrece una visión puntual acerca de la oferta de este tipo de propuesta lúdica en el momento en el cual resulta más cotizada por los jugadores, una fotografía del mercado de juegos móviles sobre la temática, precisamente cuando la fantasía se vuelve realidad con el COVID-19.

En el estudio cada componente del modelo metodológico utilizado pone en evidencia la centralidad de la información en el juego de simulación, diseñando un proceso de aprendizaje para el usuario. La primera etapa corresponde a la formación del jugador sobre la mecánica del juego mediante un documento tutorial y/o proceso experiencial que otorga la información operativa acerca de su funcionamiento. La segunda etapa se materializa durante el desarrollo del juego. Concierne la dinámica lúdica que se alimenta de información sobre la realidad simulada para la correcta interpretación de las fases de juego y del papel que desarrolla el jugador en cada una de ellas. La tercera fase corresponde a la estética, a las respuestas emotivas de los jugadores asociadas con el nivel de conocimiento alcanzado gracias a un proceso constante de toma de decisiones y elaboración de estrategias condicionadas por la información a disposición. El conocimiento se genera mediante la asunción de pautas de comportamiento que facilitan la comprensión de problemas similares cuando se presenten en la realidad y a través de los medios de comunicación.

El estudio evidencia, entre los juegos móviles, la escasa presencia de aplicaciones que tratan de pandemias mediante información realista. Tres de las cinco aplicaciones analizadas (Plague Inc., Outbreak - Infect the World y MedBot) requieren una inmersión del jugador en la narrativa de la pandemia obligándolo a adquirir, asimilar, procesar y utilizar información realista para tomar decisiones, elaborar estrategias y ganar el partido. Virus Antidote - Plague Infection e Idle Plague son proyectos comerciales que aprovechan el interés generado en el mundo de los videojuegos durante los últimos veinte años y, 
en particular, en el 2020 con la aparición del COVID-19 en China y su difusión global. Mediante la adopción de un modelo freemium para la comercialización del producto los desarrolladores de las aplicaciones pretenden monetizar el interés de las personas sobre una temática de actualidad. Sin embargo, es importante evidenciar como el mercado de los mobile games sobre pandemia es liderado por aplicaciones que proponen narrativas enfocadas en una invasión de zombies. Llama la atención la ausencia en la red de una propuesta de newsgame que trate directamente el tema de la difusión global de un virus infeccioso y la pandemia, evidenciando el peso de las mencionadas dificultades de esta categoría de juego. Como reportado en la introducción de este trabajo, el último newsgame registrado sobre la temática es del año 2009 (Killer Flu).

Esta investigación evidencia como el diseño de este tipo de aplicaciones propone una experiencia para el usuario en la cual la información es central y requiere de un aprendizaje resultante del proceso de juego. Sin embargo, es importante valorar este potencial en relación con las características, opiniones y condiciones de consumo de los usuarios de los mobile games, conocer sus opiniones, registrar las respuestas emotivas y relacionarlas con la experiencia diseñada por el desarrollador del juego.

Es necesario actualizar y profundizar el estudio sobre el valor informativo y educativo de los videojuegos que tratan de pandemias y su influencia sobre los comportamientos de las personas paralelamente al desarrollo de esta crisis epidemiológica y la futura aparición de otras similares.

\section{REFERENCIAS BIBLIOGRÁFICAS}

Alonso Martínez, D. y Navazo Ostua, P. (2019). Juegos y simulaciones en la educación actual. Revista Prisma Social, 25, pp. 537-548. Recuperado a partir de https://revistaprismasocial.es/article/view/2702

Del-Moral, M. E. (2014). Videogames: opportunities for learning/Videojuegos: oportunidades para el aprendizaje. NAER - Journal of New Approaches in Educational Research, 3(1), 1. Recuperado de https://bit.ly/3511koz

De Santis-Piras A. y Morales Morante, L. (2019). Dispositivos móviles y las multiplataforma de interacción lúdica. En A. Torres Toukumidis, L. Romero-Rodríguez y J. Salgado Guerrero (Eds.), Juegos y Sociedad: desde la interacción a la inmersión para el cambio social (pp. 6978). Ciudad de México: McGraw Hill.

Frasca, G. (2013). Newsgames: el crecimiento de los videojuegos periodísticos. En C.A. Scolari (Ed.). Homo Videoludens 2.0. De Pacman a la gamification (pp. 253-263). Collecció Transmedia XXI. Laboratori de Mitjans Interactius. Barcelona, España: Universitat de Barcelona. Recuperado de https://bit.ly/2KRDibb

Gee, J. P. (2004). Lo que nos enseñan los videojuegos sobre el aprendizaje y el alfabetismo. Málaga: Aljibe.

Herrero-Curiel, E. y Planells de la Maza, A. J. (2020). Nuevas narrativas periodísticas entre la información y la simulación lúdica: los docuwebs y los newsgames. Palabra Clave, 23(2), e2325. doi: 10.5294/pacla.2020.23.2.5

Hunicke, R., Leblanc, M. \& Zubek, R. (Julio de 2004). MDA: A formal approach to game design and game research. En D. Fu, S. Henke y J. Orkin (Presidencia), Proceedings of the AAAI Workshop on Challenges in Game AI. Nineteenth National Conference of Artificial Intelligence. San José, EE.UU.: AAAI Press. Recuperado de https://bit.ly/2KQ6X17

Ibrahim, K. (2019). Foreign language practice in simulation video games: An analysis of game-based FL use dynamics. Foreign Language Annals, 52(2), 335-357. doi: 10.1111/flan.12388 
Kurahashi, S. (Marzo de 2019). An Infectious Disease Medical Policy Simulation and Gaming. En K. Wijayasiriwardhane (Presidencia), 2019 International Research Conference on Smart Computing and Systems Engineering (SCSE). IEEE, Colombo, Sri Lanka. doi: 10.23919/ scse. 2019.8842733

Jenkins, H. (2003, 15 de enero). Transmedia Storytelling: Moving Characters from Books to Films to Video Games Can Make Them Stronger and More Compelling. MIT Technology Review. Recuperado de: https://www.technologyreview.com/s/401760/transmedia-storytelling/

Leskin, P. (13 de marzo de 2020). An old flash computer game is getting a 2nd life because of its eerie similarities to the coronavirus outbreak, and its website's CEO says it has too much of an 'educational value' to shut it down. Business Insider. New York, EE.UU.: Insider Inc. Recuperado de https://bit.ly/2zHUUnw

Luna, J. A. (4 de marzo de 2020). La fiebre de 'Plague Inc.', el videojuego para entender el coronavirus que está prohibido en China. Eldiario.es. Recuperado de https://bit.ly/3bUOsYx

Martínez Cano, F. J. (2016). Newsgames: nuevas tendencias en el periodismo ibérico. CoSECivi, 1 , 159-169. Recuperado de https://bit.ly/2z2EqGa

Martínez-Cano, F. J., Cifuentes-Albeza, R. y Ivars Nicolás, B. (2019). Videojuegos prosociales, como espacio transicional lúdico para la paz: el caso de Reconstrucción. Revista Latina de Comunicación Social, 74, 1470-1487. Doi: 10.4185/RLCS-2019-1394-77

McLuhan, M. (1996). Comprender los medios de comunicación: las extensiones del ser humano. Madrid, España: Paidós.

NEWZOO (2019). Global Games Market Report (2019). Recuperado de https://newzoo.com/ products/reports/global-games-market-report/

Papert, S. (1980). MINDSTORMS: Children, Computers, and Powerful Ideas. New York, EU.: Basic Books, Inc.

Persico D., Passarelli M., Dagnino F., Manganello F., Earp J. \& Pozzi F. (2019). Games and Learning: Potential and Limitations from the Players' Point of View. In M. Gentile, M. Allegra \& H. Söbke (Eds.), Games and Learning Alliance. GALA 2018. Lecture Notes in Computer Science, 11385 (pp. 134-145). Berlin, Alemania: Springer, Cham. doi: 10.1007/978-3-030-11548-7_13

Shaffer, D. W. (2006). How Computer Games Help Children Learn. New York, EE.UU.: Palgrave Macmillan.

Sicart, M. (2008). Newsgames: Theory and Design. In S. M. Stevens \& S. Saldamarco (Eds.), Entertainment Computing - ICEC 2008: 7th International Conference on Entertainment Computing (pp. 27-33). Pittsburgh, EU.: International Conference on Entertainment Computing (25-27 de septiembre de 2008). Berlín, Alemania: Springer.

Smith, J., Sears, N., Taylor, B. \& Johnson, M. (2020). Serious games for serious crises: reflections from an infectious disease outbreak matrix game. Globalization and Health, 16(1). doi: 10.1186/ s12992-020-00547-6

Tsai, M. H., Chang, Y. L., Shiau, J. S. \& Wang, S. M. (2019). Exploring the effects of a serious game-based learning package for disaster prevention education: The case of Battle of Flooding Protection. International Journal of Disaster Risk Reduction, 101393. doi: 10.1016/j. ijdrr.2019.101393

Urquidi Martin, A. y Calabor Prieto, M. (2014). Aprendizaje a través de juegos de simulación: un estudio de los factores que determinan su eficacia pedagógica. Edutec. Revista Electrónica de tecnología Educativa, (47), 1-15. doi: 10.21556/edutec.2014.47.75

Weimann, G. (1999). Communicating unreality: Modern media and the reconstruction of reality. Thousand Oaks, EE.UU.: Sage Publications, Inc.

Yesilyurt, O., Draghici, V., Bauer, D., Körting, L., Bildstein, A. y Bauernhansl, T. (Octubre de 2019). Game-Based Learning to Support the Development from Lean Production to Digitalised Production. En L. Elbæk (Presidencia), 13th European Conference on Games Based Learning. The University of Southern Denmark, Odense, Denmark. doi: 10.34190/GBL.19.031 